\title{
The effect of melanin on the proteolytic potential of blood under alkali esophageal burn
}

\author{
Nataliia Chornenka, Liudmyla Domylivska, Olga Kravchenko, Tetiana Koval, Liza Torgalo, \\ Alexandra Kostiuk, Nataliia Raksha, Yana Raetska, Tetiana Beregova, Ludmila Ostapchenko \\ ESC, Educational and Scientific Center "Institute of Biology and Medicine" of Taras Shevchenko National University \\ of Kyiv, Kyiv, Ukraine
}

\begin{abstract}
Caustic esophageal burns are among serious medical problems of global significance. Due to a key role in biological processes proteolytic enzymes actively involved in the pathological mechanisms underpinning the development and progression of burn-related complications. Since melanin possesses a broad spectrum of biological activities we have investigated whether this compound can influence the proteolytic activity and level of proteinase inhibitors in the blood of rats with an alkali esophageal burn. Alkaline esophageal burns, which correspond to the first and second degree of burn, were induced by $10 \%$ and $20 \% \mathrm{NaOH}$, respectively. White, nonlinear, immature (4 weeks old) rats were used in the experiment. Total proteolytic activity was measured using casein as a substrate. The activities of $\alpha 1$ antitrypsin and $\alpha 2$-macroglobulin were measured considering the degree of inhibition of hydrolysis of N-benzoyl-L-arginineethyl ester. The fraction of serine proteinases was obtained by affinity chromatography on a benzamidine sepharose column. The qualitative composition of serine proteinases fraction was analyzed by zymography technique. According to the data
\end{abstract}

Correspondence: Nataliia Chornenka, ESC "Institute of Biology and Medicine" of Taras Shevchenko National University of Kyiv,

Volodymyrska Str. 64/13, 01601, Kyiv, Ukraine

Tel.: +38 0959368198

E-mail: nata.chornenka24@gmail.com

Key words: Melanin; Proteolysis; Alkali esophageal burn.

Conflict of Interest: The Authors declare no potential conflict of interests.

Received for publication: 26 September 2019.

Accepted for publication: 1 May 2020.

${ }^{\circ}$ Copyright: the Author(s), 2020

Licensee PAGEPress, Italy

Journal of Biological Research 2020; 93:8577

doi:10.4081/jbr.2020.8577

This article is distributed under the terms of the Creative Commons Attribution Noncommercial License (by-nc 4.0) which permits any noncommercial use, distribution, and reproduction in any medium, provided the original author(s) and source are credited. obtained, the pathogenesis of alkaline esophageal burn is accompanied by a significant increase in the total proteolytic activity, activity of serine proteinases, and activity of $\alpha 1$-antitrypsin and $\alpha 2$-macroglobulin compared with the control rats. The present results clearly indicated that melanin is able to normalize the proteolytic homeostasis by affecting the activity of serine proteinases and the level of proteinase inhibitors in the plasma of rats with alkali esophageal burns.

\section{Introduction}

One of the relevant areas of modern medicine and biology is the study of proteolytic enzymes, which are involved in the regulation of multiple biological processes in all living organisms. Proteinases related to such important functions as protein turnover, cellular and tissue structuring, defense, modulation of protein-protein interactions, cellular signaling and so on. ${ }^{1}$ The ubiquity of proteinases makes them an important target for the pharmaceutical industry as potential drug targets or as diagnostic and prognostic biomarkers. Considering the essential role of proteinases in the maintenance of homeostasis, the alterations of their activity underlie multiple pathological conditions, namely burns.

Nowadays esophageal burns are generally recognized, as one of the most challenging clinical situations in gastroenterology. According to statistics, the majority of chemical poisoning involves children younger than 5 years as a result of unintentional, accidental ingestion of caustic substances. ${ }^{2}$ The pathogenesis of alkaline esophageal burn is strongly associated with the changes in proteolysis that promote the development of postburn complications. ${ }^{3}$ Excessive activation of proteolysis is one of the factors contributing to the inflammation and impaired healing processes under esophageal burns. ${ }^{4}$ Numerous studies have shown that chronic wounds contain neutrophils that secrete gelatinases and elastases leading to inactivation of growth factors and tissue damage. Despite the established role of proteolysis in the development of burn-related disorders and impaired wound healing, the underlying mechanisms, which mediate the significant and long-term activation of proteolytic enzymes have not been elucidated. Due to the burn-associated metabolic disorders, the search for new approaches and the development of new medicines with a pronounced therapeutic effect and a high safety profile meet current medical needs. Taking into account a great number of studies regarding biological activities of melanin ${ }^{5-7}$ as well as the results of our earlier work, ${ }^{8}$ the current research aimed to investigate the influence of melanin on the main proteolytic parameters under alkali esophageal burn. 


\section{Materials and Methods}

\section{Animals and experimental design}

A total of 75 white, nonlinear, immature (4 weeks old) rats weighing 90-110 g were used in the experiment. All animal procedures were approved by the Ethical Committee of Taras Shevchenko National University of Kyiv. Animal care and manipulation were conducted in accordance with the general ethical principles of the Council of Europe Convention for the Protection of Vertebrate Animals used for Experimental and other Scientific Purposes (1997), and other international agreements and national legislation in this field. The experiment started after 7 days of the animal acclimation in the animal facility of Taras Shevchenko National University of Kyiv, maintained under constant conditions of temperature $\left(22 \pm^{\circ} \mathrm{C}\right)$, humidity $(60 \pm 5 \%)$, and light $(12 \mathrm{~h}$ light/12 h dark cycle). Standard rodent food and water were provided ad libitum.

Alkaline Esophageal Burn (AEB) was induced using sodium hydroxide $(\mathrm{NaOH})$. Alkaline esophageal burns, corresponding to the first- and second-degree of burn, were induced by $10 \%$ and $20 \% \mathrm{NaOH}$, respectively. $\mathrm{NaOH}$ solution was administered using a probe that was injected on a depth of $4 \mathrm{~cm}$ from the upper incisors of the animal. The control rats were treated with an equal volume of sterilized ultra-pure water in the same way. ${ }^{9}$ On the $2^{\text {nd }}$ day after injection of $\mathrm{NaOH}$ half of the animals from each group was randomly selected and subjected to the treatment with melanin (1 $\mathrm{mg} / \mathrm{kg}$ ), which was administered every other day for next 14 days. We used melanin that was produced by Antarctic black yeast-like fungi Nadsoniella nigra strain X1. ${ }^{10}$ The other animals from the groups as well as the control rats received injection of sterilized ultra-pure water in accordance with the scheme described above. The animals were sacrificed at $7^{\text {th }}, 15^{\text {th }}$ and $21^{\text {st }}$ day of experiment.

Thus, there were 5 experimental groups with 15 animals in each: i) control; ii) first-degree Alkaline Esophageal Burn (AEB1); iii) second-degree Alkaline Esophageal Burn (AEB2); iv) animals with first-degree Alkaline Esophageal Burn treated with melanin (AEB1+melanin); v) animals with second-degree Alkaline Esophageal Burn treated with melanin (AEB2+melanin).

\section{Samples collection}

Blood samples were collected in routine biochemical test tubes. Serum samples were prepared by centrifugation at $1000 \mathrm{~g}$ for $30 \mathrm{~min}$ of previously incubated (for $30 \mathrm{~min}$ at $37^{\circ} \mathrm{C}$ ) blood samples. Plasma samples were prepared by collecting blood in tubes containing 3.8\% sodium citrate. After centrifugation at $800 \mathrm{~g}$ for $40 \mathrm{~min}$, the supernatants were taken and stored in small aliquots at $-80^{\circ} \mathrm{C}$ until analysis.

\section{Determination of some parameters of the proteolytic system}

Total proteolytic activity was measured using casein as a substrate. ${ }^{11}$ To determine the activity of serine proteinases, the inhibitor of serine proteinases Phenylmethanesulfonyl Fluoride (PMSF) at the final concentration of $2 \mathrm{mM}$ was added to the reaction mixture. The activity of $\alpha 1$-antitrypsin and $\alpha 2$-macroglobulin were measured based on the degree of inhibition of hydrolysis of N-Benzoyl-L-Arginine-Ethyl Ester (BAEE). ${ }^{12}$ The protein concentration was determined by the method of Bradford using bovine serum albumin as a standard. ${ }^{13}$ The fraction of trypsin-like serine proteinases was obtained by affinity chromatography on benzamidine sepharose column pre-equilibrated with working buffer 20
$\mathrm{mM}$ Tris- $\mathrm{HCl}$ buffer, $\mathrm{pH}$ 8.0. ${ }^{14}$ Elution of the adsorbed proteins was carried out using $50 \mathrm{mM}$ glycine- $\mathrm{HCl}$ buffer, $\mathrm{pH} 3.0$ containing $1 \mathrm{M} \mathrm{NaCl}$. The sample was loaded and the fraction of trypsinlike serine proteinases were collected at a flow rate of $120 \mathrm{~mL}$ per hour. Zymography assay was performed according to the method. ${ }^{15}$ Separating gel $(12 \% \mathrm{w} / \mathrm{v})$ was polymerized in the presence of fibrinogen $(1 \mathrm{mg} / \mathrm{mL})$.

Statistical analysis

All values were expressed as mean \pm SD for each group $(n=15)$. Statistical analysis was performed using one-way analysis of variance (ANOVA). Differences were considered to be statistically significant when $\mathrm{p}<0.05$.

\section{Results}

Considering that the development of burn-related complications is generally associated with proteolytic imbalance, the first our goal was to isolate the fraction of serine proteinases from the plasma of rats with AEB and to determine their concentration. It was observed that burn progression is accompanied by a decrease in the concentration of serine proteinases on the $7^{\text {th }}$ day of firstdegree AEB (by $74 \%$ ) and on the $15^{\text {th }}$ and $21^{\text {st }}$ days of seconddegree AEB (by $41 \%$ and 17\%) (Figure 1).

According to the data, the concentration of serine proteinases increased only on the $15^{\text {th }}$ day in the case of first-degree AEB (by $20 \%$ ) and on the $7^{\text {th }}$ day in the case of second-degree AEB (by $70 \%$ ).

Values are expressed as mean $\pm \mathrm{SD}(\mathrm{n}=15) ;{ }^{*} \mathrm{p}<0.05$ significantly different from the control group; $\# \mathrm{p}<0.05$ significantly different from appropriate AEB group

The administration of melanin to the animals with first-degree AEB resulted in the increase in the concentration of serine proteinases on the $7^{\text {th }}$ day compared with the result in the group of AEB rats. The concentration of serine proteinases on the $15^{\text {th }}$ day was higher than in the group of rats with AEB as well as the control group. The treatment with melanin AEB2 rats led to a significant decrease in the concentration of serine proteinases on the $7^{\text {th }}$ day of the experiment compared to the untreated animals but did not influence this parameter on the $15^{\text {th }}$ and $21^{\text {st }}$ days. It is important to note that melanin mediated the decrease in the concentration of serine proteinases on the $15^{\text {th }}$ and $21^{\text {st }}$ days compared to the control.

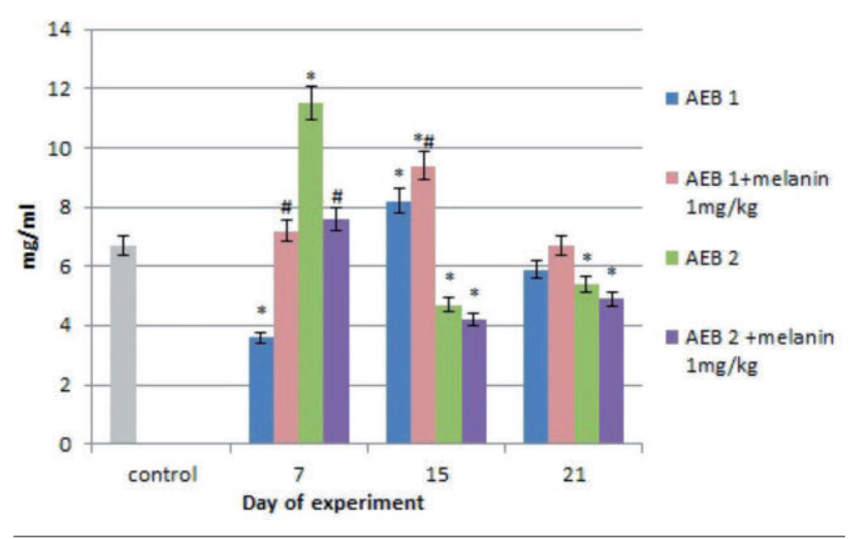

Figure 1. Concentration of serine proteinases in the plasma of rats with Alkaline Esophageal Burns and of rats treated with melanin: AEB1 - first-degree Alkaline Esophageal Burn; AEB2 - seconddegree Alkaline Esophageal Burn. 
Next, the fraction of trypsin-like serine proteinases was analyzed by zymography technique. Second-degree AEB is known to cause more serious tissue damage. Taking into account this fact, we analyzed the qualitative composition of serine proteinases isolated from the plasma of rats with second-degree AEB and AEB rats treated with melanin. As can be seen from Figure 2, the pathogenesis of alkali esophageal burn was accompanied by the changes in the qualitative composition of serine proteinases compared to the result in the control group. The main difference was the appearance of low molecular weight fragments, namely with molecular weight about $36 \mathrm{kDa}$ and $23 \mathrm{kDa}$.

In general, the appearance of active enzymes that were not found in the plasma of the control rats may be the evidence of the activation of proteolysis or/and destructive processes associated with cell disruption. When the AEB animals were administrated with melanin, the less pronounced intensity of proteolytic bands was detected. This observation may indicate the decrease in the activity of serine proteinases under the influence of melanin and can be considered as a positive feature.

During the next stage of the study, the total proteolytic activity in the plasma of rats with AEB as well as rats treated with melanin was estimated. It was found a significant increase in the total proteolytic activity at all investigated time points (Figure 3).

Values are expressed as mean $\pm \mathrm{SD}(\mathrm{n}=15) ;{ }^{*}<0.05$ significantly different from the control group; $\# \mathrm{p}<0.05$ significantly different from appropriate AEB group

The most expressed activity was detected on the $7^{\text {th }}$ day of the experiment - the total proteolytic activity was increased by $247 \%$ and by $294 \%$ in the animals with first- and second-degree AEB, respectively. The total proteolytic activity in the plasma of rats with AEB was decreased under the influence of melanin but remained elevated compared to the control. The obtained results are coherent with the data of zymography assay and reflect the positive effect of melanin on the proteolytic balance.

Considering that the serine proteinases play a crucial role in the pathogenesis of burns, ${ }^{16}$ it seemed of interest to determine their activity under alkaline esophageal burn development. It was shown an increase in the activity of serine proteinases by $355 \%, 342 \%$, and $269 \%$, respectively on the $7^{\text {th }}, 15^{\text {th }}$, and $21^{\text {st }}$ days of firstdegree burn development (Figure 4).

Values are expressed as mean $\pm \mathrm{SD}(\mathrm{n}=15) ;{ }^{*} \mathrm{p}<0.05$ significantly different from the control group; $\# \mathrm{p}<0.05$ significantly different from appropriate AEB group

In the case of a second-degree burn, the activity of serine proteinases was higher by $468 \%, 443 \%$, and $435 \%$ on the $7^{\text {th }}, 15^{\text {th }}$, and $21^{\text {st }}$ days of the experiment. We have observed a significant inhibi-

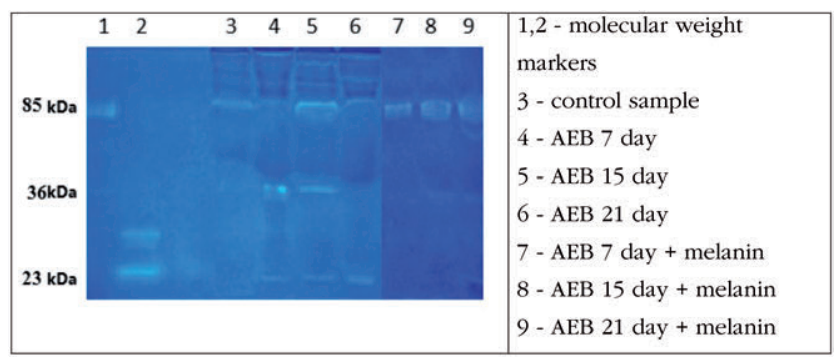

Figure 2. Enzymogram of the fraction of trypsin-like serine proteinases isolated from the plasma of rats with second-degree Alkaline Esophageal Burn (AEB) and of rats treated with melanin. tion of serine proteinases activity in the group of AEB rats, which were treated with melanin.

The increase in the activity of serine proteinases could partly be due to the disorder of the ratio between enzymes and their inhibitors. Therefore, the next goal was to investigate the activity of $\alpha 2$-macroglobulin and $\alpha 1$-antitrypsin under AEB. The obtained results are summarized in Table 1. As seen from Table, the activity of $\alpha 1$-antitrypsin in the plasma of rats with first-degree AEB was higher than the control value and statistically significant during the whole experiment, whereas a statistically significant change of this parameter was detected only on the $15^{\text {th }}$ day of second-degree AEB. Our finding has revealed an increase in the activity of $\alpha 2-$ macroglobulin on the $7^{\text {th }}$ day of the experiment (by $73 \%$ ) in the case of first-degree AEB and on the $15^{\text {th }}$ day (by 60\%) as well as on the $21^{\text {st }}$ day (by $88 \%$ ) in the case of second-degree AEB.

It was found that the administration of melanin led to normalization of $\alpha 1$-antitrypsin activity, which returned to the control value on the $7^{\text {th }}, 15^{\text {th }}$, and $21^{\text {st }}$ days of first-degree AEB. The decrease of this parameter (by $38 \%$ ) compared with the control

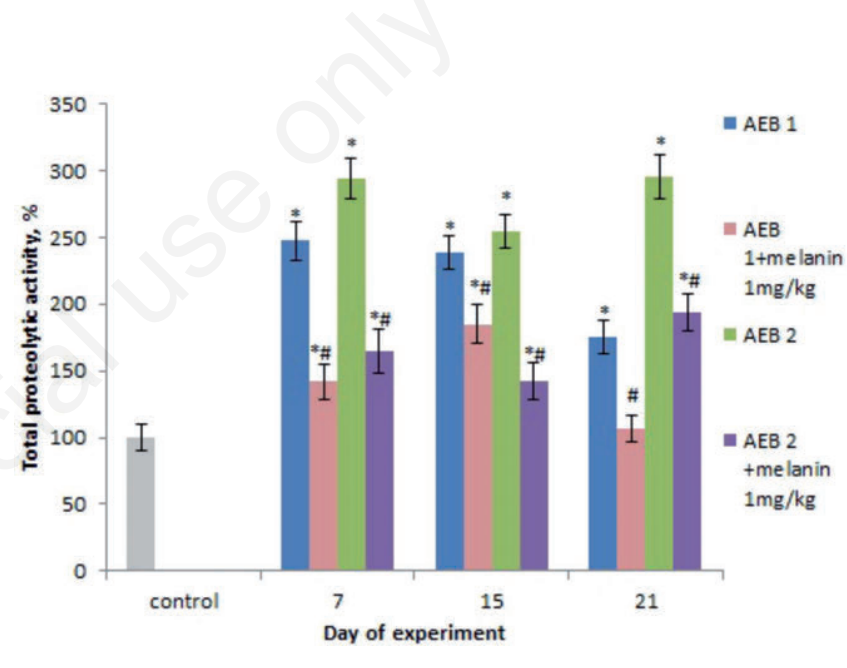

Figure 3. Total proteolytic activity in the plasma of rats with Alkaline Esophageal Burn and of rats treated with melanin: AEB1 - first-degree alkaline esophageal burn; AEB2 - second-degree alkaline esophageal burn.

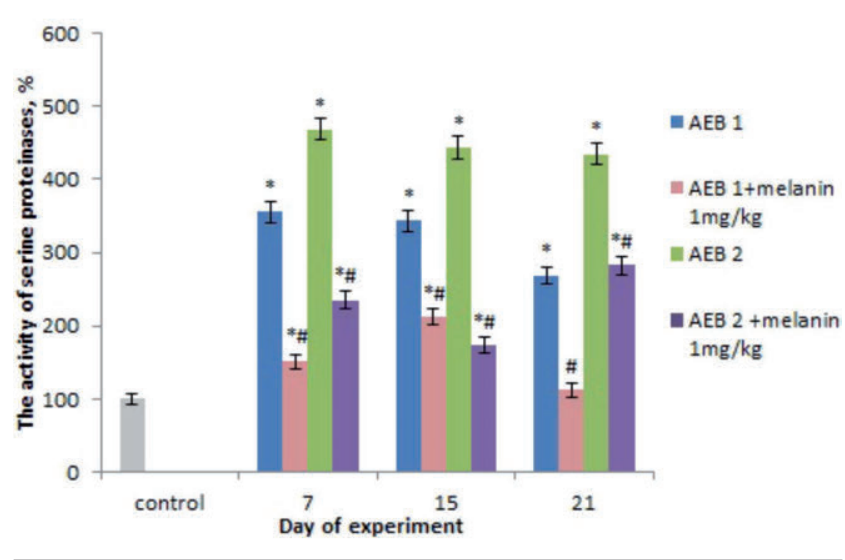

Figure 4. Activity of serine proteinases in the plasma of rats with Alkaline Esophageal Burn and of rats treated with melanin: AEB1 - first-degree Alkaline Esophageal Burn; AEB2 - second-degree Alkaline Esophageal Burn. 
Table 1. Activity of $\bigotimes 1$-antitrypsin and $\alpha 2$-macroglobulin in the blood serum of rats with first-degree Alkaline Esophageal Burn (AEB1), second-degree Alkaline Esophageal Burn (AEB2) and of rats treated with melanin (AEB1 + melanin, AEB2 + melanin).

\begin{tabular}{|c|c|c|c|c|}
\hline & AEB 1 & AEB1 + melanin & AEB2 & AEB2 + melanin \\
\hline \multicolumn{5}{|c|}{ 1-antitrypsin activity, (IU / ml) } \\
\hline Control & $32.8 \pm 3.8$ & $32.8 \pm 3.8$ & $32.8 \pm 3.8$ & $32.8 \pm 3.8$ \\
\hline $7^{\text {th }}$ day & $54.1 \pm 3.4^{*}$ & $30.1 \pm 2.4^{\#}$ & $36.9 \pm 3.6$ & $23.6 \pm 2.2^{* \#}$ \\
\hline $15^{\text {th }}$ day & $52.8 \pm 5.7^{*}$ & $27.4 \pm 2.3^{\#}$ & $52.8 \pm 4.3^{*}$ & $28.2 \pm 2.5 \#$ \\
\hline $21^{\text {st }}$ day & $46.8 \pm 7.2^{*}$ & $30.9 \pm 3.2^{\#}$ & $31.4 \pm 2.4$ & $27.3 \pm 2.4$ \\
\hline \multicolumn{5}{|c|}{ 2-macroglobulin activity, (IU / ml) } \\
\hline Control & $5.3 \pm 0.9$ & $5.3 \pm 0.9$ & $5.3 \pm 0.95$ & $5.3 \pm 0.9$ \\
\hline $7^{\text {th }}$ day & $9.2 \pm 1.1^{*}$ & $5.6 \pm 1.0^{\#}$ & $6.4 \pm 1.2$ & $4.8 \pm 0.9$ \\
\hline $15^{\text {th }}$ day & $7.7 \pm 1.7$ & $4.9 \pm 0.9^{\#}$ & $8.5 \pm 1.2^{*}$ & $5.4 \pm 0.9^{\#}$ \\
\hline $21^{\text {st }}$ day & $5.2 \pm 1.9$ & $4.4 \pm 0.9$ & $10.0 \pm 1.4^{*}$ & $6.5 \pm 1.0^{\#}$ \\
\hline
\end{tabular}

Values are expressed as mean $\pm \mathrm{SD}(\mathrm{n}=15) ;{ }^{*} \mathrm{p}<0.05$ significantly different from the control group; $\# \mathrm{p}<0.05$ significantly different from appropriate AEB group.

group was observed on the $7^{\text {th }}$ day in the group of second-degree AEB animals treated with melanin.

The activity of $\alpha 2$-macroglobulin in the serum of AEB rats treated with melanin was lower than in the appropriate AEB group. Thus, the activity of $\alpha 2$-macroglobulin decreased by $64 \%$ and $57 \%$ on the $7^{\text {th }}$ and $15^{\text {th }}$ days in the rats with first-degree AEB and by $57 \%$ and $53 \%$ on the $15^{\text {th }}$ and $21^{\text {st }}$ days in the rats with seconddegree AEB.

\section{Discussion}

Nowadays the corrosive esophageal burns belong to a serious medical problem that is prevalent not only in developing countries but also widespread in well-developed countries. Uncontrolled activation of proteolysis is considered to be a key event in the pathogenesis of esophageal burns. Among the enzymes, which are actively involved in the progression of esophageal burns and the development of burn-related complications are serine proteinases a family of enzymes with a broad spectrum of functions.

Our finding has revealed a significant increase in the concentration of serine proteinases only on the $15^{\text {th }}$ day of first-degree AEB and on the $7^{\text {th }}$ day of second-degree AEB (Figure 1). It is important to note that we have detected a decrease in the concentration of serine proteinases on the $7^{\text {th }}$ day of first-degree AEB and on the $15^{\text {th }}$ and $21^{\text {st }}$ days of second-degree AEB. Such a result can be explained, first of all, by the formation of complexes of enzymes with inhibitors and their further elimination from the bloodstream.

The data obtained indicate a marked increase in the total proteolytic activity (Figure 3 ) and activity of serine proteinases in the plasma of rats with AEB (Figure 4). The elevated activity can result from the development of oxidative stress, which is typical for the pathogenesis of alkali-mediated burns of the esophagus. It causes the disruption of cell membranes and the release of the proteinases in the bloodstream. Additionally, an excessive amount of ROS via regulation of redox-sensitive pathways could influence the synthesis of both natural inhibitors of proteolytic enzymes and proteinases $^{17}$

The analysis of the qualitative composition of trypsin-like serine proteinases derived from the plasma of rats with AEB has revealed a great number of proteins that possess the enzymatic activity (Figure 2). Considering that plasmin/plasminogen is one of the major serine proteinases in the blood, the accumulation of proteolytic active molecules could result from the cleavage of this enzyme. Structurally damaged plasmin/plasminogen and their fragments could potentially retain proteolytic activity but contrary to the native molecules, they are not influenced by serpin-family inhibitors. For these reasons, the formation and accumulation of degraded forms of enzymes seemed to be an important pathogenic mechanism of disease progression.

A key mechanism of the regulation of the activity of proteinases involves the interaction of the enzymes with tissue inhibitors. Moreover, the restoration of damaged tissues depends on the balance between the level of proteolytic enzymes and their inhibitors. The long-term disorder of this balance can provoke pathological healing. The data obtained in this study indicate that the development of burns is accompanied by the alteration of the activity of $\alpha 1$-antitrypsin and $\alpha 2$-macroglobulin (Table 1). The increase in the activity of the inhibitors in the serum of rats with both first- and second-degree AEB could be the compensatory mechanism in response to the enhancement of proteolysis.

Despite the numerous efforts, the treatment of chemical burns of the esophagus represents one of the most complex problems, especially in the field of pediatric medicine. The main goal of treatment at the early stage of burn is to prevent stricture formation by suppressing the inflammation, bacterial translocation as well as restoring the proteolytic balance in the esophagus and in the plasma. ${ }^{18}$ Melanin due to a broad spectrum of biological activities has attracted attention as a promising therapeutic agent in the treatment of pathologies associated with oxidative stress and inflammation. We found that the treatment of AEB rats with melanin led to the normalization of the proteolytic balance in the blood by decreasing the activity of serine proteinases and restoring the activity of the most abundant proteinase inhibitors $\alpha 1$-antitrypsin and $\alpha 2$ macroglobulin. This may be due to the well-known antioxidant properties of melanin, which causes the interruption of the process of lipid peroxidation and inhibits the formation of free radicals.

\section{Conclusions}

To our knowledge, this is the first research investigating the proteolysis under alkali esophageal burns development. The prote- 
olytic imbalance, manifested by a significant increase in the total proteolytic activity, the activity of serine proteinases and changes in the level of proteinase inhibitors was observed. Our findings provide an indication that melanin is able to normalize the proteolytic homeostasis by affecting the activity of proteolytic enzymes in the plasma of rats with alkali esophageal burns. Considering the obtained data, melanin could represent a promising therapeutic agent in the treatment of esophageal burns and burn-mediated complications.

\section{References}

1. McCarty SM, Percival SL. Proteases and Delayed Wound Healing. Adv Wound Care 2013;2:438-7.

2. Wang Y, Beekman J, Hew J, et al. Burn injury: Challenges and advances in burn wound healing, infection, pain and scarring. Adv Drug Deliv Rev 2018;123:3-17.

3. Ishchuk TV, Savchuk AM, Rayetska YB. Proteinase functioning of mucous membrane of esophagus after chemical burn. Physiol J 2015;5:61-7.

4. Sarrazy V, Billet F, Micallef L. Mechanisms of pathological scarring: Role of myofibroblasts and current developments. Wound Repair Regen 2011;1:10-5.

5. Golyshkin DV, Falalyeyeva TM, Chyzhanska NV, et al. White blood count of rats under stress-induced stomach lesions and the prophylactic administration of melanin. Ukr Antarct J 2015;14:180-4.

6. Zeng-Yu Y, Jian-Hua Q. Comparison of Antioxidant Activities of Melanin Fractions from Chestnut Shell. Molecules 2016;21:487.

7. Kunwar A, Adhikary B, Jayakumar S, Barik A. Melanin, a promising radioprotector: Mechanisms of actions in a mice model. Toxicol Appl Pharmacol 2012;264:202-11.

8. Chornenka N, Raetska Ya, Grebinyk D, et al. Protective antioxidant effect of melanin against chemical burn-induced esophageal injury. Biomed Res Ther 2018;5:2712-8.

9. Raetska YaB, Ishchuk.TV, Dzhus OI, et al. Experimental modeling of 1 st and 2 nd degrees alkali esophageal burn in immature rats. Biol System 2013;1:116-20.

10. Permyakova N, Zheltonozhskaya T, Beregova T, Klymchuk D, Falalyeyeva T. Micellar nanocarriers for anticancer drug melanin. Mol Crystals Liquid Crystals 2016;640, 122-33.

11. Crystals and Liquid Crystals, 640, 122-133. Hummel BC. Amodified spectrophotometric determination of chymotrypsin, trypsin and thrombin. Can J Bioch Physiol 1959;37:1393-9.

12. Nartykova VF, Paskhina TS. Unified method for determining the activity of $\alpha 1$-antitrypsin and $\alpha 2$ - macroglobulin in serum (plasma) of human blood. Questions Med Chem 1979;25:4949.

13. Bradford MM. A rapid and sensitive method for quantities of utilizing the principle of protein binding. Anal Bioch 1976;86:193-200.

14. Affinity Chromatography. Principles and Methods. Amersham Pharmacia Biotech AB; 2001. Pp. 89-96.

15. Ostapchenko L, Savchuk O, Burlova-Vasilieva N. Enzyme electrophoresis method in analysis of active components of hemostasis system. Adv Biosci Biotech 2011;2:20-6.

16. Sarrazy V, Billet F, Micallef L. Mechanisms of pathological scarring: Role of myofibroblasts and current developments. Wound Repair Regen 2011;1:10-5.

17. Davies PL, Spiller OB, Beeton ML. Relationship of proteinases and proteinase inhibitors with microbial presence in chronic lung disease of prematurity. Thorax 2010;65:246-51.

18. Velnar T, Bailey T, Smrkolj V. The Wound Healing Process: an Overview of the Cellular and Molecular Mechanisms. J Int Med Res. 2009;37:1528-42. 